\title{
The Geographical Enigma of Top Achievements in Weightlifting
}

\author{
Shlomo Hareli ${ }^{*}$, Gadi Katzir², Simcha Lev-Yadun ${ }^{3}$ \\ ${ }^{1}$ Department of Business Administration, University of Haifa, Haifa, Israel \\ ${ }^{2}$ Department of Evolutionary and Environmental Biology, Faculty of Natural Sciences, University of Haifa, Haifa, Israel \\ ${ }^{3}$ Department of Biology and Environment, Faculty of Natural Sciences, University of Haifa-Oranim, Kiriat Tivon, Israel \\ Email: ^shareli@univ.haifa.ac.il
}

How to cite this paper: Hareli, S., Katzir, G. \& Lev-Yadun, S. (2020). The Geographical Enigma of Top Achievements in Weightlifting. Advances in Anthropology, 10, 48-60. https://doi.org/10.4236/aa.2020.101004

Received: November 16, 2019

Accepted: January 5, 2020

Published: January 8, 2020

Copyright (C) 2020 by author(s) and Scientific Research Publishing Inc. This work is licensed under the Creative Commons Attribution International License (CC BY 4.0).

http://creativecommons.org/licenses/by/4.0/

\begin{abstract}
We examined the geography of top achievements in weightlifting in the Olympic Games for men (1992-2016), and women (2000-2016). Geographic origins of men are restricted to countries with a salient center around the Balkan and the Caucasus areas. This is especially evident for weightlifters in the upper body weight categories. Top achievements of women are more widely spread geographically, yet with clustering in the south-eastern part of Asia. Data on participation in the Olympic Games suggest that this unbalanced geographical spread of men is unlikely to be explained by cultural preferences but rather by specific physical adaptations. This conclusion receives further support from considering weight to height ratio of athletes winning gold medals relative to the average in the general population.
\end{abstract}

\section{Keywords}

Weightlifting, Geographic Origins, Physical Adaptations, Olympic Games

\section{Introduction}

Specific physical adaptations of humans that are related to geography are well-known from various places. For example, people from the high mountains of Tibet and Bolivia have a better adaptation to lower oxygen concentrations attributed to their genotypes (Beall, 2001, 2006). People from Montenegro are taller on average than people from most other regions (Popovic, 2017). Such geographical adaptations often have implications for athletic performances. For example, runners from the highlands of eastern Africa dominate in track events upwards of $800 \mathrm{~m}$ as well as in international cross-country and road racing events (Scott, Moran, Wilson, Goodwin, \& Pitsiladis, 2004; Wilber \& Pitsiladis, 
2012). When it comes to sprinters of short distance (100 m), athletes of African origin born in the USA or in the Caribbean islands, dominate this type of sports (Tucker, Santos-Concejero, \& Collins, 2013). Among top swimmers, there is a conspicuous lack of athletes of African origin (Lev-Yadun, 2015).

Here we examine the possibility that male weightlifters also originate from a rather limited geographical region. We focused on male weightlifters, since females, in general, and females who participate in what can be considered as a classic male sport, in particular, are stereotyped. Accordingly, their choice to become weightlifters is more likely to be affected by societal rules and cultural constraints (Krane, Choi, Baird et al., 2004). This may strongly overshadow any potential effect of a physical adaptation. Nevertheless, we present data for female weightlifters as well, as it serves as a control for our analysis. We will first describe in brief the rules of weightlifting competitions in the Olympic Games and describe the physical demands and characteristics of Olympic weightlifting. We then provide data depicting the geographical dispersion of top male and female competitors in the Olympics across the Olympic Games from 1992 to 2016. A restricted geographical spread of top male weightlifters, can serve as an indication of a specific adaptation.

\section{Weightlifting Competition-Rules and Physical Demands}

In a weightlifting competition, each weightlifter has to perform two types of competitive lifts: 1) the snatch, and 2) the clean and jerk. In each of these lifts, the weightlifters are required to generate extremely high peak forces and muscle contractile rates of force development and, as a result, high peak power and contractile impulses (Garhammer, 1993). The snatch and the clean and jerk lifts are complex whole-body movements encompassing a series of high-intensity muscular contractions. During these lifts, weightlifters perform power outputs that are considered to be unmatched by any other athlete (Storey \& Smith, 2012). The snatch requires the weighted barbell to be lifted from the floor, using a wide handgrip, to an overhead position in one continuous movement. Then, the lifter straightens the legs in one out of several accepted styles. By contrast, the clean and jerk is a two-part lift. In the first part, the lifter lifts the barbell from the floor to a racked position across the deltoids, without resting fully on the clavicles. During the jerk the lifter raises the barbell to a stationary position above the head, finishing with straight arms and legs. The clean and jerk style enables $18 \%-20 \%$ heavier loads to be lifted than the snatch (Storey \& Smith, 2012). Both lift types include six phases and each athlete is entitled to three attempts of each lift type in a competition.

Over the years, lifters' body weight classes changed, but since 1998, the recognized body weight classes are: for men $\leq 56 \mathrm{~kg}, \leq 62 \mathrm{~kg}, \leq 69 \mathrm{~kg}, \leq 77 \mathrm{~kg}, \leq 85 \mathrm{~kg}$, $\leq 94 \mathrm{~kg}, \leq 105 \mathrm{~kg}$, and $>105 \mathrm{~kg}$; and for women $\leq 48 \mathrm{~kg}, \leq 53 \mathrm{~kg}, \leq 58 \mathrm{~kg}, \leq 63 \mathrm{~kg}$, $\leq 69 \mathrm{~kg}, \leq 75 \mathrm{~kg}$, and $>75 \mathrm{~kg}$. Athletes have to be weighed during a one-hour window that begins two hours before the start of their competition's session. The athlete's relative placing within their respective body weight class is determined 
by their competition total, which is the sum of their highest recorded snatch, and clean and jerk lifts. When a tie occurs, the athlete with the lower bodyweight is declared the winner. If two athletes lift the same total weight and have the same bodyweight, the winner is the athlete who lifted the total weight first (International-Weightlifting-Federation, 2018).

Like many Olympic sports, weightlifting sets unique physical and mental demands on its athletes (Sherouse, 2016). Reviewing the literature, Storey and Smith (2012) described the unique physical challenges faced by top weightlifters as well as their typical anthropometric characteristics. Light to middle-weight male weight lifters (i.e. $\leq 56 \mathrm{~kg}$ to $\leq 85 \mathrm{~kg}$ ) are somatotyped as predominately ectomorphic or mesomorphic with body fat percentages ranging between $0 \%$ and $5 \%$. By contrast, male weightlifters in the heavy to unlimited weight classes (i.e. $\leq 94 \mathrm{~kg}$ to $>105 \mathrm{~kg}$ ) tend to be more endomorphic mesomorphs with body fat percentages of $17 \%$ or higher. Anthropometric data on female weightlifters is less comprehensive, yet the limited data suggest that the body fat percentage of female weightlifters is double than that of male weightlifters of a similar body mass. However, elite male and female weightlifters exhibit a lower body fat percentage when compared with lower level competitors of a similar total body mass. Thus, the resulting difference in lean body mass becomes a major contributing factor to the divergent neuromuscular responses seen between male and female and elite versus non-elite weightlifters.

In comparison to other strength and power athletes of a similar body mass and composition, weightlifters are shorter in height, have a proportionally shorter arm span and tibial lengths, and a larger biacromial breadths. Such atypical anthropometric characteristics, allow for two critical mechanical advantages when lifting maximal loads. 1) The mechanical torque that is required to lift a given load is lower due to shorter lengths of the resistance lever, i.e. the arms; and 2) the amount of muscular work (weight $\times$ distance) required to lift a given load is decreased following the reduction in the vertical distance that the barbell must be displaced. Furthermore, the shorter body dimensions coincide with a greater mean skeletal muscle cross-sectional area, which is advantageous to weightlifting performance (Storey \& Smith, 2012).

Storey and Smith (2012) further suggested that whereas the compositional body characteristics of weightlifters in the lighter weight categories are comparable to weight restricted wrestlers and athletes competing in the sprinting and jumping events of athletics, weightlifters in the heaviest categories possess similar body compositions to heavyweight wrestlers, power lifters, discus, shot put and hammer throwing athletes.

Considering the fact that weightlifting poses unique physical demands and that top weightlifters are characterized by typical anthropometric characteristics, we examined if top male weightlifters in heavy weights share a specific common geographical origin or if the talent of lifting extreme weights is evenly dispersed in the human population. As mentioned above, female weightlifting, like wom- 
en's sports more generally, is more amenable to societal and cultural influences (Krane et al., 2004). This can also explain why it was introduced into the Olympic Games rather late (in the 2000 Olympic Games) and why across the games there are fewer female athletes than men in this field.

\section{Materials and Methods}

Using the records from the Sports-Reference website (2016) we extracted data about the Olympic Games of 1992-2016 (the post-Soviet period). Specifically, for each Olympic game, we compiled data about the number of countries participating, number of sport fields practiced in the Olympic Games, and total number of competing athletes. We also counted the countries that sent weightlifters to each of the Olympic Games during that period and the number of sports for which these countries had at least one competing Olympic athlete. In addition, we compiled data about medal winners in each of the weightlifting categories including locality of birth, the country that each medal winner represented and population size at the relevant year for each data point [World Bank Organization website (2017); Trading Economics website (2018); Worldmeters website (2018)]. Finally, we also extracted from the Sports-Reference website (2016) the weight and height of each gold medal wining athlete. This was done in order to assess if these athletes have a different weight to height ratio than the normal. Data for normal adult weight to height ratio was taken from the Disabled World Web site (2017). Since both for weight and height figures appear as a range, we used the middle point of each range of height and weight.

\section{Results}

\subsection{Weightlifting and Countries with Weightlifters}

Weightlifting is one of the longstanding sports of the modern Olympic Games with many participating athletes and countries (Storey \& Smith, 2012). Indeed, as shown in Table 1, between the Olympic Games of 1992 and 2016, which are the focus of the present analysis, the number of men weightlifters participating in the games ranged between 150 and 244 and of women, between 85 and 103, per event. However, women weightlifters started to participate in the Olympic Games only in the year 2000. Across these years, between 38\% and $44 \%$ of the countries participating in the Olympic Games, had weightlifters among their athletes (Sports-Reference, 2016).

Weightlifters participating in the Olympic Games come from all the populated continents and islands (see Figure 1 and Figure 2) with some variation in terms of the average number of weightlifters sent to an Olympic Games event. For men, Russia and South Korea sent the highest number of weightlifters while countries from South and Central America, most of Africa and Asian islands, Canada and Scandinavia, sent few weightlifters (Figure 1). For women (Figure 2), variation is smaller, since the maximal number of female weightlifters allowed to participate in the Olympic Games for each country was four. Fewer 


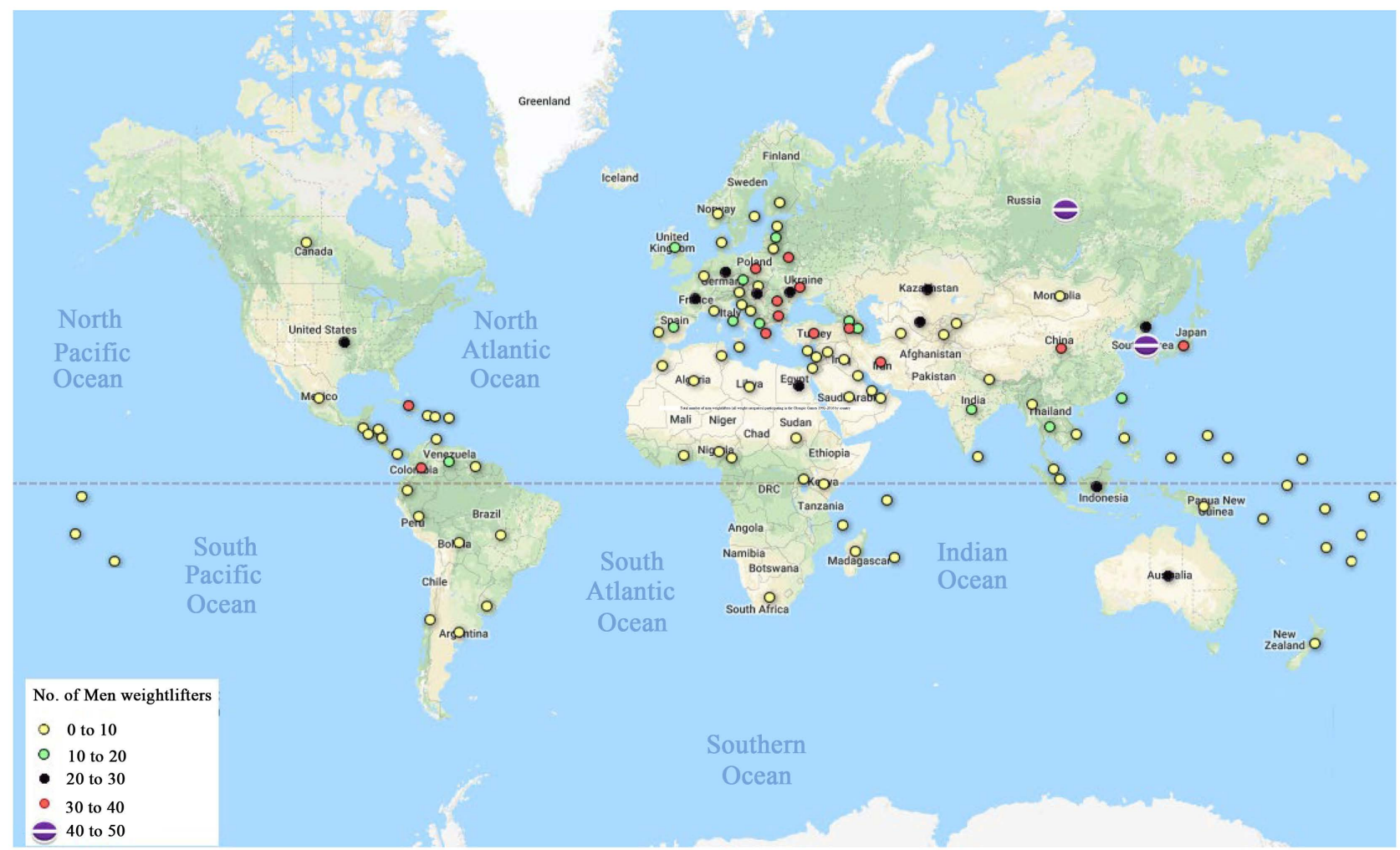

Figure 1. Total number of men weightlifters (all weight categories) participating in the Olympic Games 1992-2016 by country.

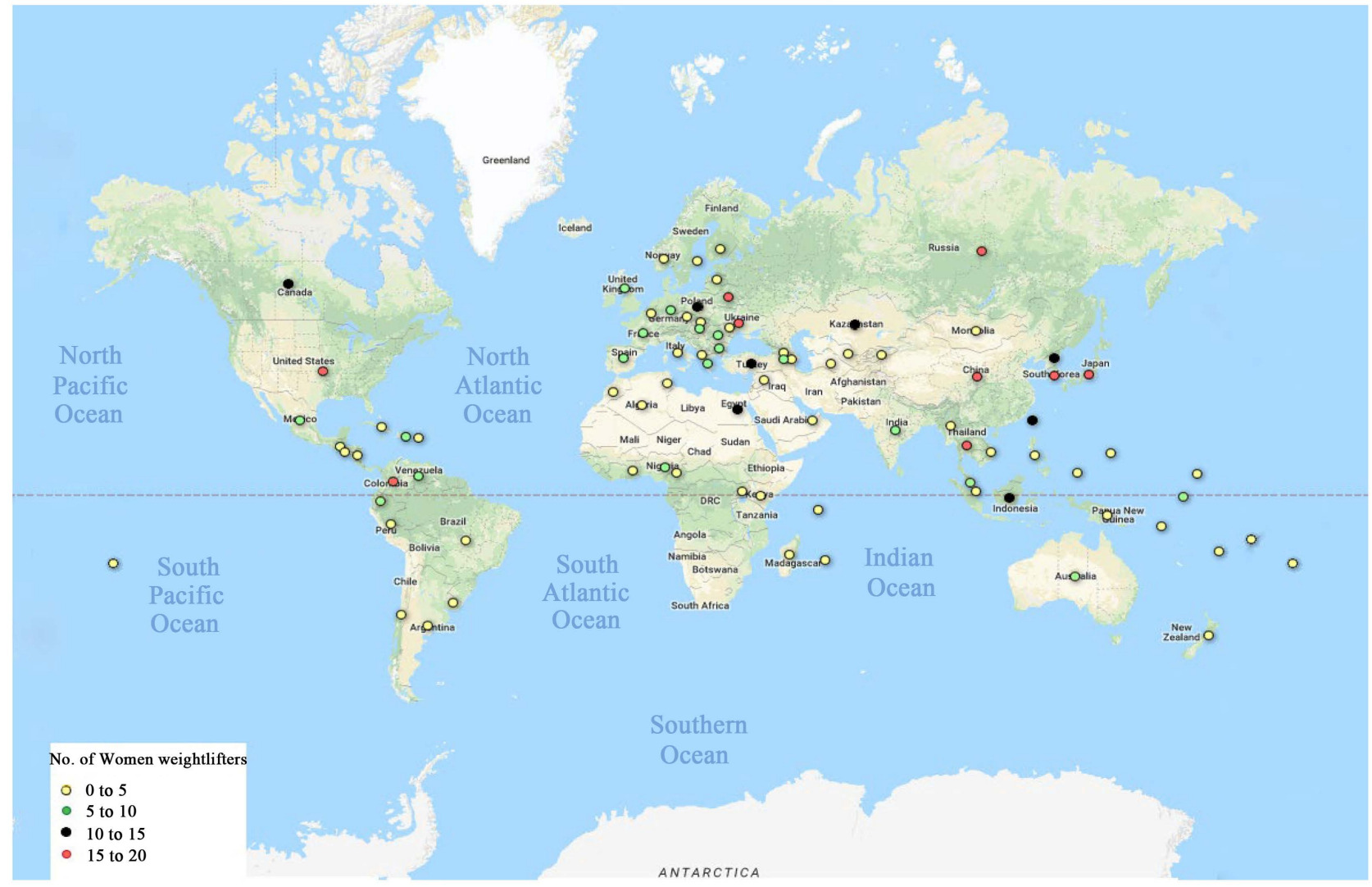

Figure 2. Total number of women weightlifters (all weight categories) participating in the Olympic Games 1992-2016 by country. 
Table 1. Number of countries, athletes and sport types in the Olympic Games between 1992 and 2016 in relation to the number of countries with weightlifters.

\begin{tabular}{|c|c|c|c|c|c|c|c|c|}
\hline Year & $\begin{array}{c}\text { Number of } \\
\text { sports-Men }\end{array}$ & $\begin{array}{c}\text { Number of } \\
\text { sports-Women }\end{array}$ & $\begin{array}{l}\text { Countries } \\
\text { with } \\
\text { weightlifters }\end{array}$ & $\begin{array}{l}\text { Number of } \\
\text { participating } \\
\text { countries }\end{array}$ & $\begin{array}{c}\text { Number of } \\
\text { weightlifters-Men }\end{array}$ & $\begin{array}{c}\text { Total } \\
\text { number of } \\
\text { male athletes }\end{array}$ & $\begin{array}{c}\text { Number of } \\
\text { weightlifters-Women }\end{array}$ & $\begin{array}{c}\text { Total number } \\
\text { of female } \\
\text { athletes }\end{array}$ \\
\hline 1992 & 27 & 23 & 69 & 169 & 244 & 6659 & 0 & 2721 \\
\hline 1996 & 28 & 25 & 77 & 197 & 243 & 6820 & 0 & 3521 \\
\hline 2000 & 31 & 31 & 76 & 200 & 161 & 6579 & 85 & 4068 \\
\hline 2004 & 31 & 32 & 79 & 201 & 164 & 6257 & 85 & 4303 \\
\hline 2008 & 31 & 32 & 84 & 204 & 166 & 6290 & 87 & 4610 \\
\hline 2012 & 31 & 32 & 84 & 205 & 150 & 5864 & 103 & 4653 \\
\hline 2016 & 30 & 32 & 92 & 207 & 152 & 6147 & 103 & 5037 \\
\hline
\end{tabular}

Since 2000, women weightlifters were allowed to participate in the Olympic Games and each competing nations were allowed to send a maximum of 10 competitors comprised of six men and four women, hence the drop in number of men weightlifters beginning in the Olympic Games of the year 2000.

female weightlifters came from the southern part of central and South America, East and South of Africa and some Islands in Asia. For both men and women, the numbers of weightlifters sent to the Olympic Games is not in high correspondence with top achievements of weightlifters, as will be shown below.

Among countries with Olympic competing weightlifters, larger countries take part in a greater number of sports then smaller ones (Figure 3 and Figure 4). However, top achievements of weightlifters are not associated strongly with geographical spread or with spread as a function of total number of sports that represented a given country.

\subsection{Winners of Medals in Weightlifting in the Olympic Games}

For men, across weight categories, Medal types, and Olympic Games there is a majority of medal winners from countries from the Caucasus, Balkan, China, Russia, Iran and some countries of the former Soviet Union (Figure 5). Highest absolute number of gold medal winners (see Table 2), is taken by China followed by Bulgaria, Iran, Georgia, and Russia but relative to the country's population, Bulgaria comes on top, followed by Albania, and Georgia, with Armenia, Moldova and Belarus following. China, with highest number of gold medals in weightlifting (in low body weight classes) is lowest ranking when achievements are considered relative to population size. Thus, countries of the Caucasus and the Balkan areas dominate the top achievements. We further searched the specific birthplace of the athletes (Figure 6). The geographical pattern is maintained and even strengthens, as a large proportion of Gold winners of huge countries such as Russia, are from the regions close to the Caucasus and the Balkan areas.

Considering weightlifters of the three top body weight categories only, the geographical distribution of winners narrows even further to the Caucasus and the Balkan areas with 9 out of the 15 gold medal winners coming from this region. Thus, for example, Iranian weightlifters tend to be from this area and not 


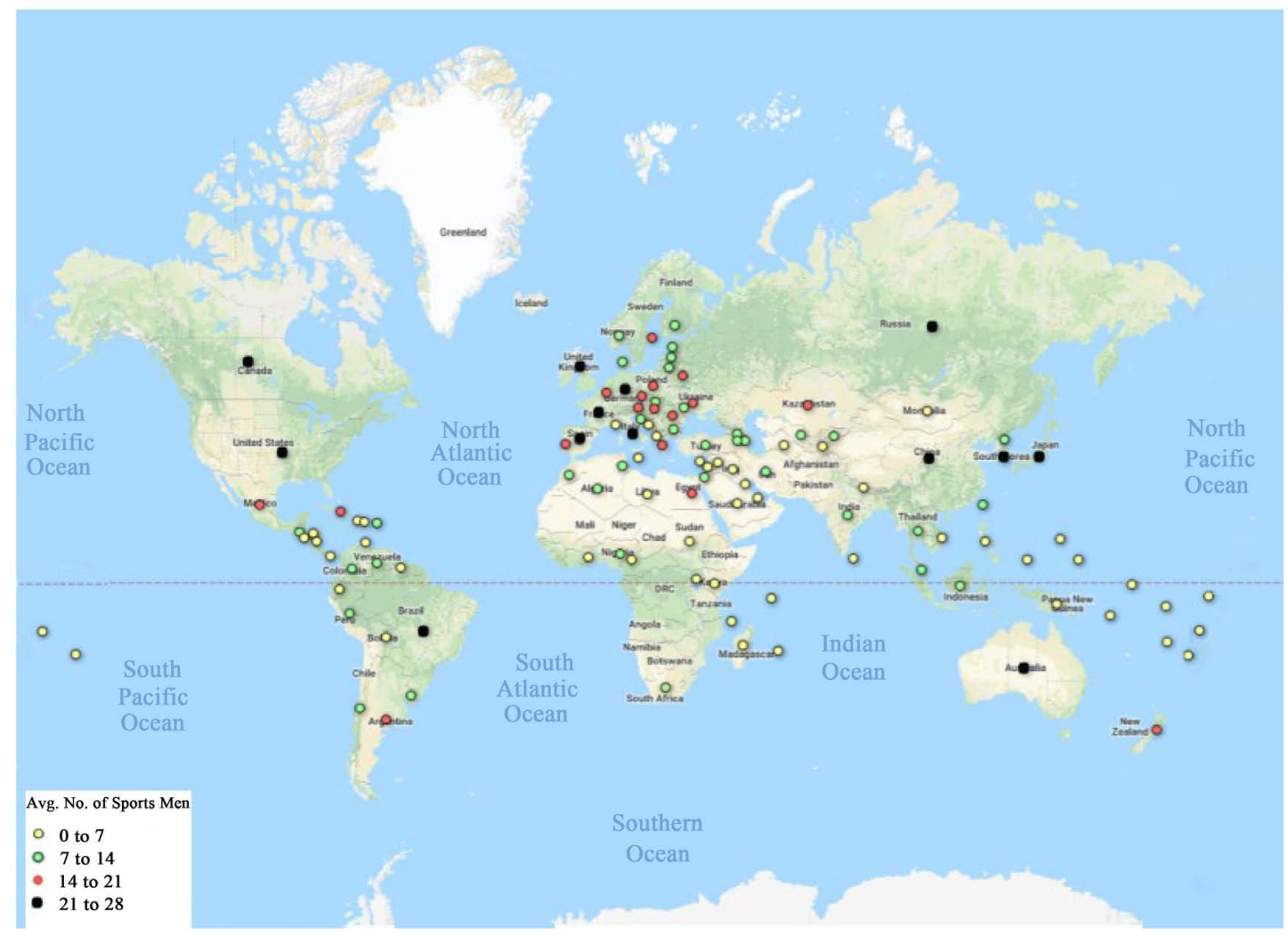

Figure 3. Average number of sports for countries sanding weightlifters to the Olympic games 1992-2016-men.

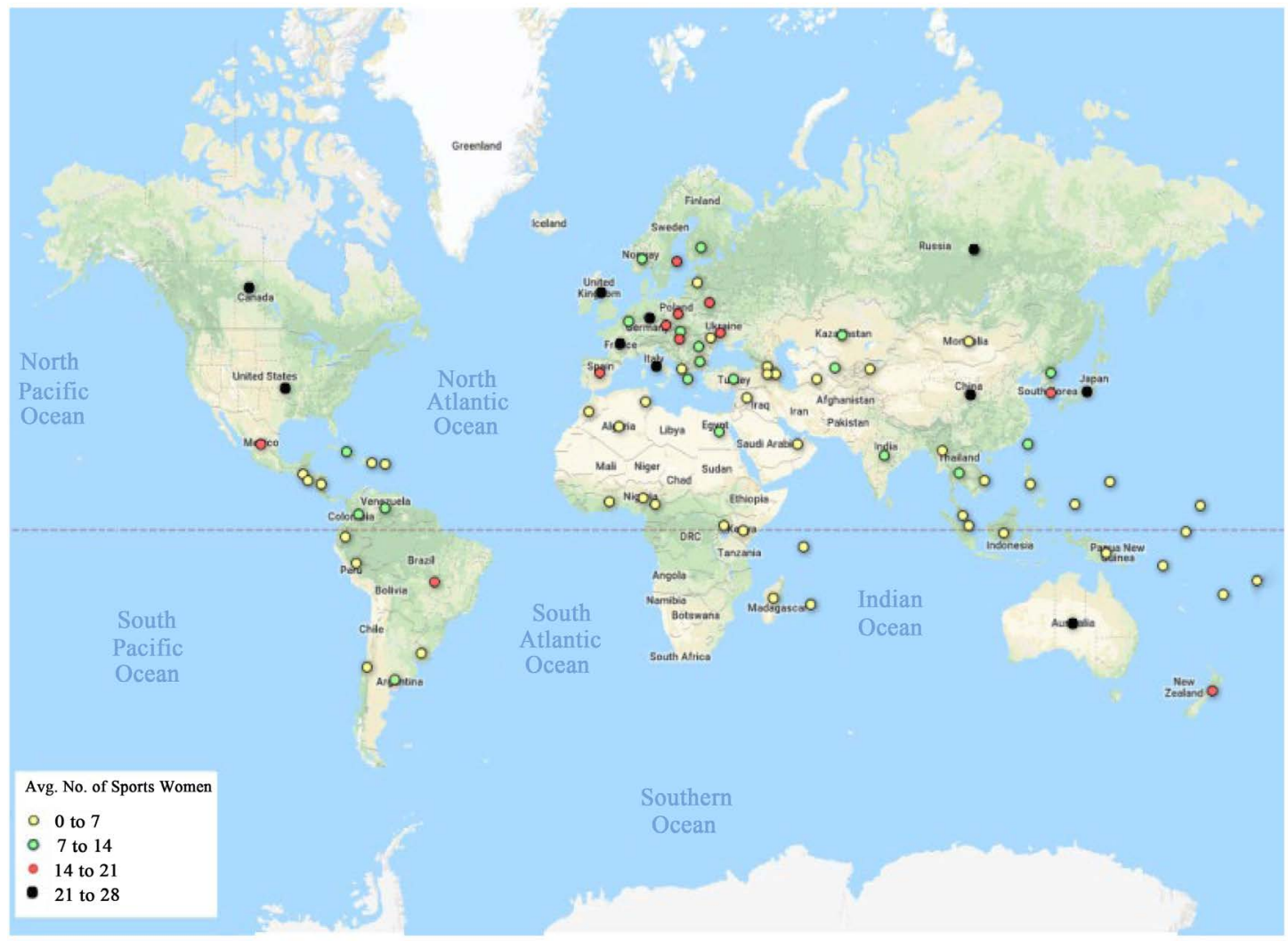

Figure 4. Average number of sports for countries sanding weightlifters to the Olympic games 2000-2016-women. 


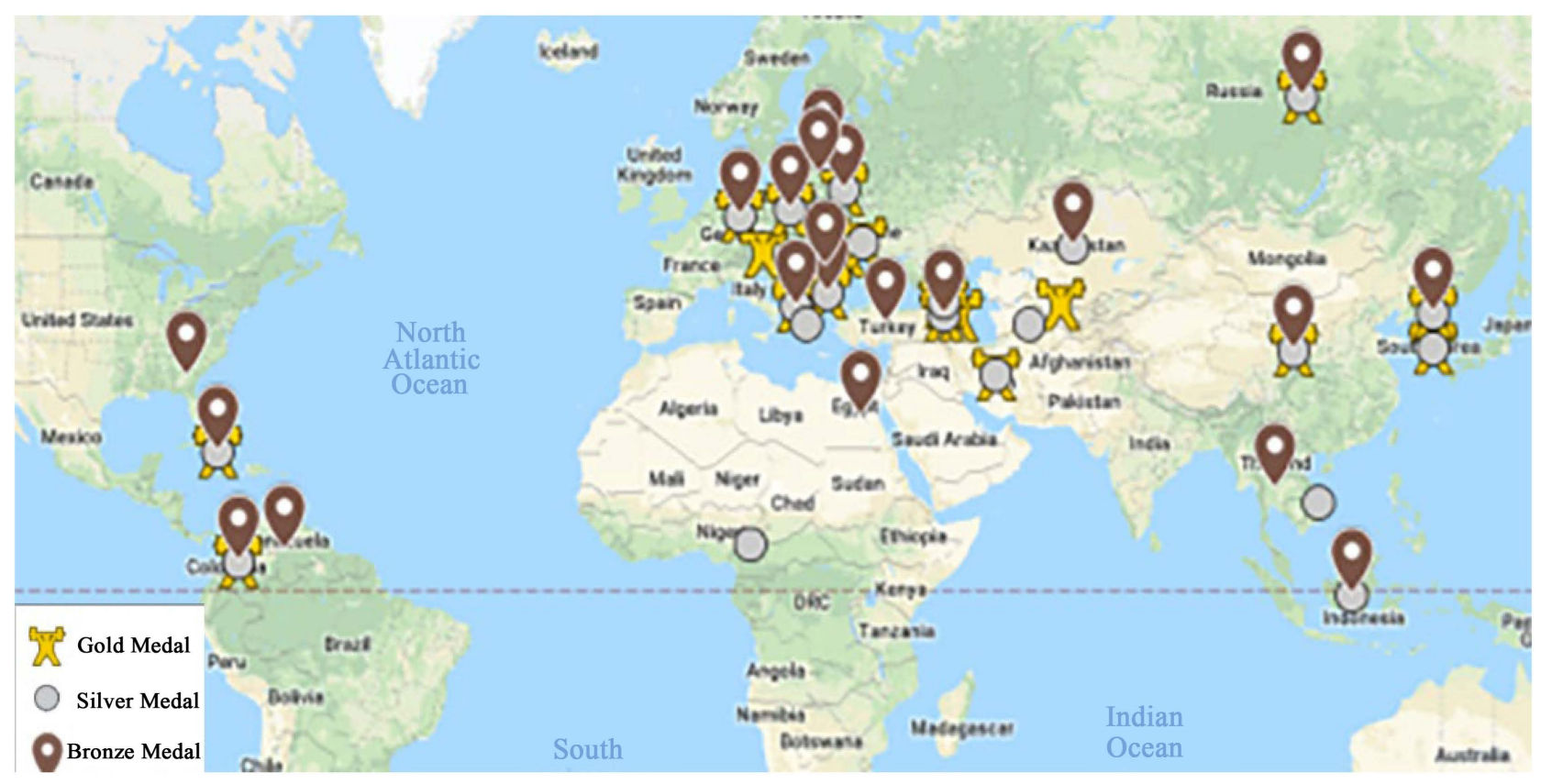

Figure 5. Countries winning a medal in the men weightlifting competition in the Olympic Games 1992-2016.

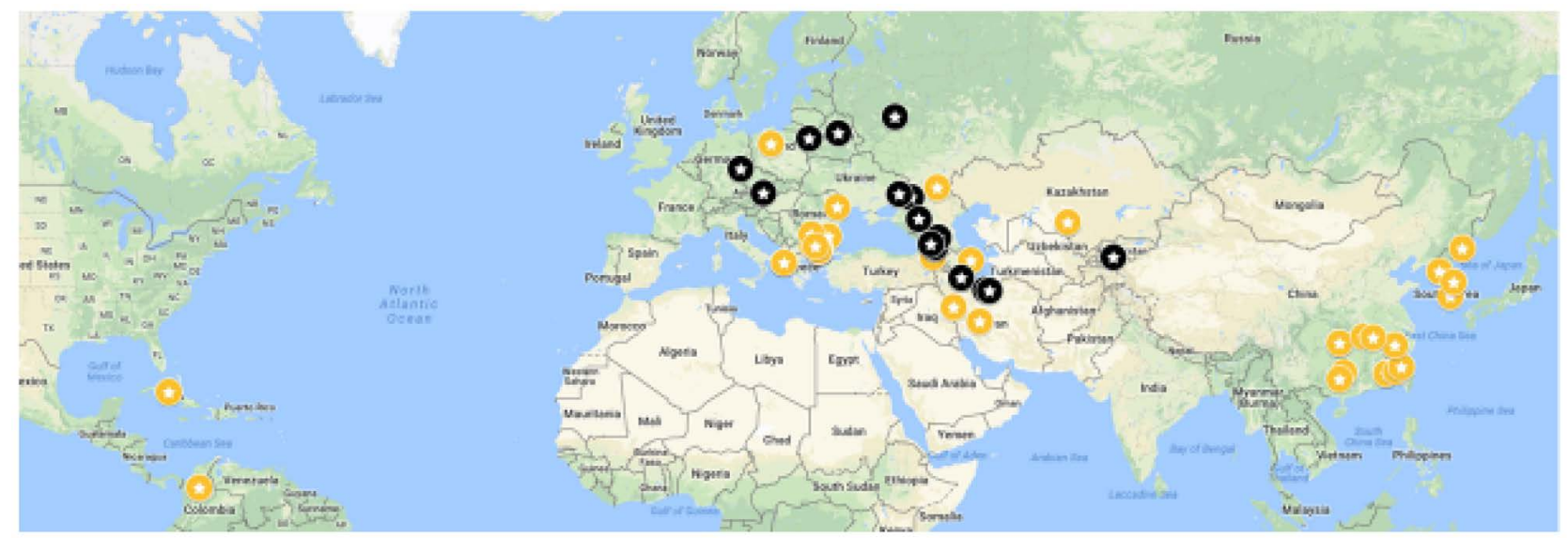

Seven lower body weight categories

( Three top body weight categories

Figure 6. Geographical origin of gold medals winners in weightlifting—all bodyweight categories men.

from the southern or western regions of the country. Of interest is the fact that several large countries with a high number of athletes at the Olympic Games (USA, Canada, Brazil, France, the UK, Germany, Spain) are not among the winners of gold medals in weightlifting. To summarize the results for male weightlifters, a high proportion of top achievers concentrate in the Balkan and the Caucasus areas. By contrast, as regards to female weightlifters, the geographical origin of top achievers is very different.

Across weight categories, medal types, and Olympic Games there is a large majority of female medal winners from China and East Asia while athletes from the Balkan and Caucasus areas are not among the female winners (Figure 7). 
Table 2. Total number of gold medals in weightlifting for all categories per country and relative to population size.

\begin{tabular}{|c|c|c|c|c|c|}
\hline \multicolumn{3}{|c|}{ Men } & \multicolumn{3}{|c|}{ Women } \\
\hline Country & $\begin{array}{l}\text { Number } \\
\text { of Medals }\end{array}$ & $\begin{array}{l}\text { Number of } \\
\text { Medals relative } \\
\text { to population } \\
\text { size in Millions }\end{array}$ & Country & $\begin{array}{l}\text { Number } \\
\text { of Medals }\end{array}$ & $\begin{array}{l}\text { Number of } \\
\text { Medals relative } \\
\text { to population } \\
\text { size in Millions }\end{array}$ \\
\hline China & 13 & 0.010 & China & 18 & 0.014 \\
\hline Bulgaria & 8 & 0.991 & Thailand & 5 & 0.075 \\
\hline Iran & 7 & 0.095 & North Korea & 3 & 0.058 \\
\hline Georgia & 4 & 0.927 & Colombia & 1 & 0.025 \\
\hline Russia & 4 & 0.027 & Mexico & 1 & 0.010 \\
\hline Albania & 3 & 0.947 & South Korea & 1 & 0.020 \\
\hline South Korea & 2 & 0.043 & Spain & 1 & 0.021 \\
\hline North Korea & 2 & 0.081 & Taiwan & 1 & 0.042 \\
\hline Belarus & 2 & 0.203 & Turkey & 1 & 0.015 \\
\hline Poland & 2 & 0.053 & Ukraine & 1 & 0.021 \\
\hline Moldova & 1 & 0.270 & US & 1 & 0.004 \\
\hline Colombia & 1 & 0.021 & & & \\
\hline Germany & 1 & 0.012 & & & \\
\hline Azerbaijan & 1 & 0.102 & & & \\
\hline Cuba & 1 & 0.091 & & & \\
\hline Austria & 1 & 0.120 & & & \\
\hline Armenia & 1 & 0.290 & & & \\
\hline Uzbekistan & 1 & 0.031 & & & \\
\hline Ukraine & 1 & 0.022 & & & \\
\hline
\end{tabular}

${ }^{*}$ Since some countries won more than one medal during the relevant period and population size changed, for these countries, average number of gold medals per population size in millions is calculated by dividing the number of Medals by average population size during the relevant years.

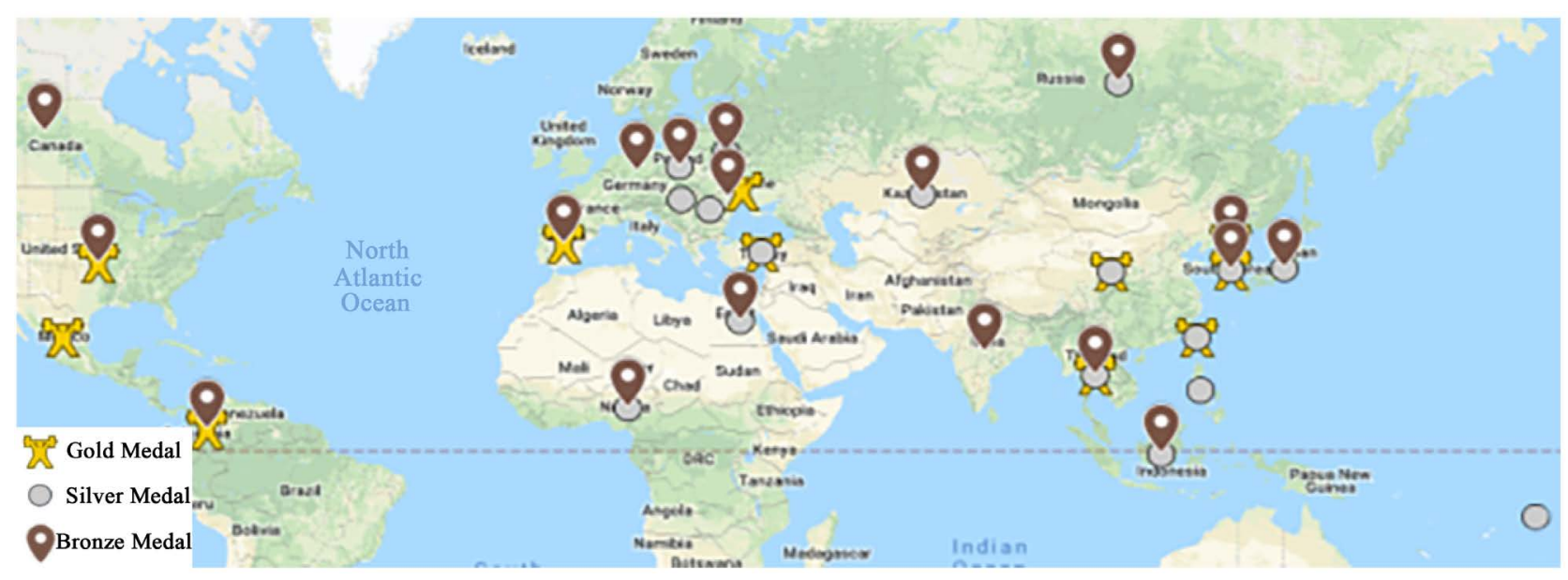

Figure 7. Countries winning a medal in the women weightlifting competition in the Olympic Games 1992-2016. 
Concerning absolute number of gold medals, China is on top, followed by Thailand and North Korea. In Numbers relative to population size, Thailand comes on top, followed by North Korea, and China.

As to birthplace of female weightlifters, East Asia strongly dominates top body weight categories as well as the lower ones (Figure 8). Finally, for gold medal winners only, we plotted weight to height ratio for each weight category and the normal weight to height ration. As shown in Figure 9, for men and Figure 10, for women, weightlifters deviate substantially from normal weight to height ratio. This deviation is particularly large for the top weight categories such that their weight to height ratio is strongly skewed toward higher weight relative to height.

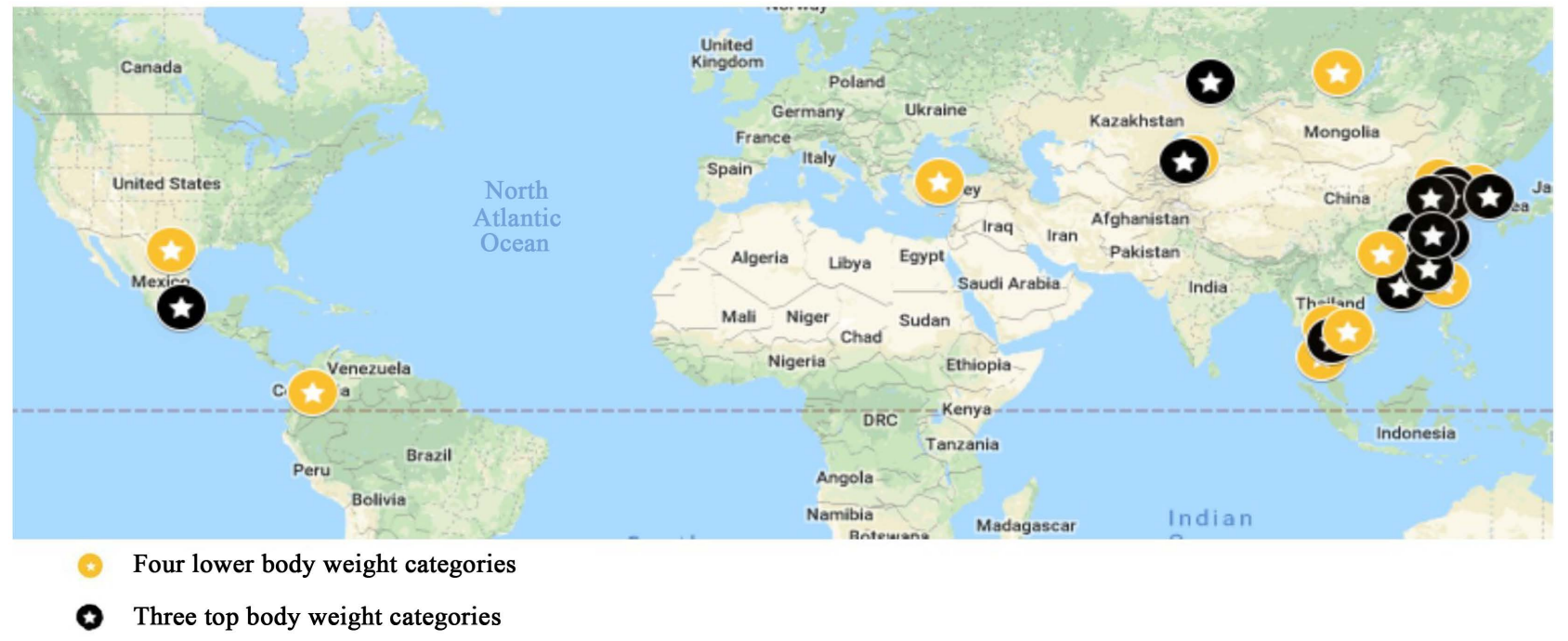

Figure 8. Geographical origin of gold medals winners in weightlifting-all bodyweight categories women.

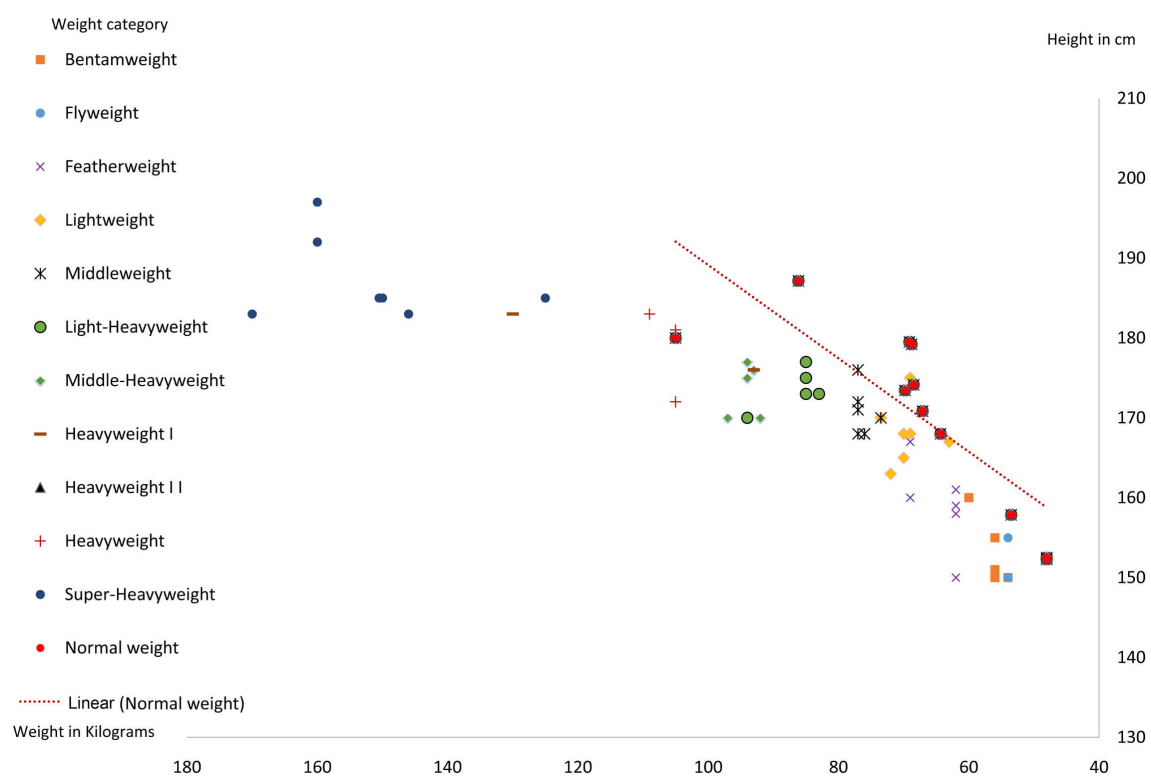

Figure 9. Weight to height Ratio of men wining gold medals for each weight category. 


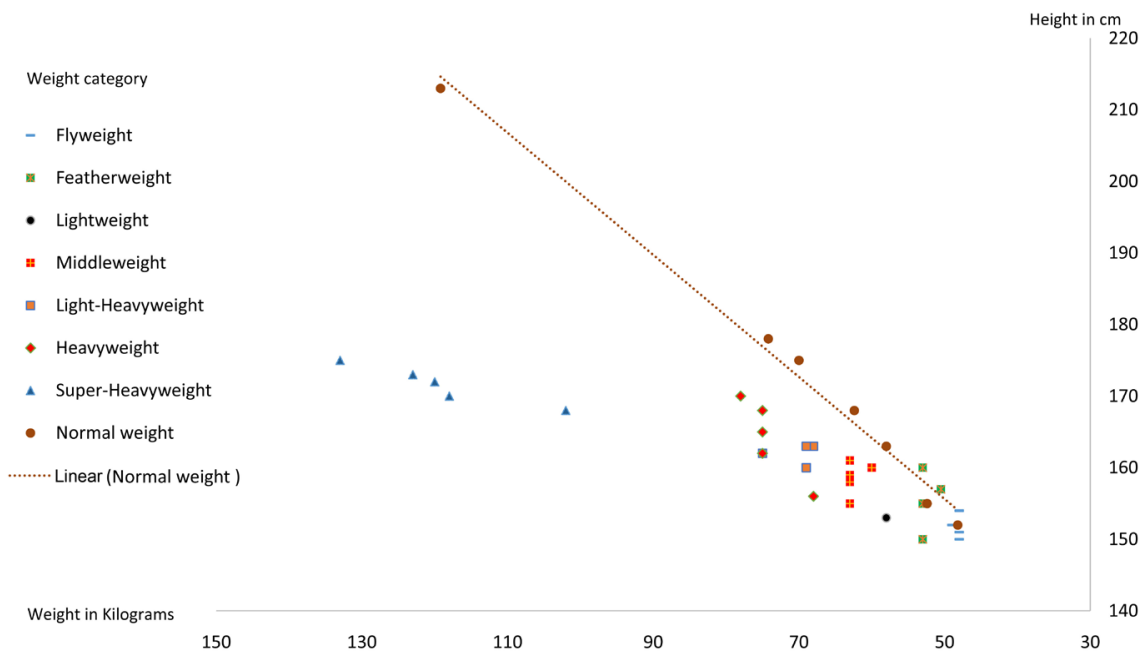

Figure 10. Weight to height ratio of women wining gold medals for each weight category.

In sum, geographic origins of men are restricted to countries with a salient center around the Balkan and the Caucasus areas. This is especially evident for weightlifters in the upper body weight categories. Top achievements of women are more widely spread geographically, yet with clustering in the south-eastern part of Asia.

\section{Discussion}

Specific physical adaptations of human populations, associated with the physical nature of their native countries, translate into advantages in specific sports, as is reflected in top achievements in these fields. This is the case, for example, for long distance runners originating from the highlands of eastern Africa (Scott, Moran, Wilson, Goodwin, \& Pitsiladis, 2004; Wilber \& Pitsiladis, 2012), short distance sprinters of African origin born in the USA or in the Caribbean islands, who dominate this type of sports (Tucker, Santos-Concejero, \& Collins, 2013), and top swimmers which do not include among them athletes of African origin (Lev-Yadun, 2015). The present paper suggests that the same is true of top male weightlifters who tend to originate from the Caucasus and Balkan areas.

Like for many other sport fields, top weightlifters have unique physical characteristics enabling them to achieve their top performances (Storey \& Smith, 2012). This lends itself to the possibility that top weightlifters, like top athletes in other fields such as long distance running, are endowed with geographically related adaptations associated with the desired physical characteristics. The results of our analysis, which focused on the geographical distribution of top achievers in weightlifting, provide suggestive evidence that this is indeed the case. Specifically, both men and women who are top weightlifters originate from a rather restricted geographic area. However, the top male and female weightlifters center of origin is in different geographical regions. Whereas male top weightlifters tend to cluster in the Caucasus and Balkan areas, top female weightlifters originate in East Asia. Further, top weightlifters are endowed with unique physical 
characteristics as reflected by their weight relative to their height, which strongly deviates from normal weight to height ratio, especially for the heavier weight categories. This suggests that some specific adaptation related to the geographic origin of the athletes is responsible for this advantage. This is more likely the case for men than for women since female sports are influenced strongly by cultural and societal rules (Krane et al., 2004) and hence it is more difficult to control for such possible effects of geographical spread of athletes. Based on our results, future research may focus more closely on examining the possible genetic factors that may be responsible for relevant adaptations endowing top male weightlifters. As suggested by the number of weightlifters sent to the Olympics by countries such as Canada, Brazil, France, the UK, Germany, Spain and Italy in general, and the USA in particular, the lack of winners coming from these countries is unlikely to be attributed to cultural preferences. This conclusion can be further substantiated by the fact that weight lifting is the second most popular exercise activity in the USA (U.S. Bureau of Labor Statistics, Division of Occupational Employment Statistics, n.d.).

\section{Conclusion}

Data on participation in the Olympic Games suggest that there is an unbalanced geographical spread of men among top achievers. This is unlikely to be explained by cultural preferences but rather by specific physical adaptations. This conclusion receives further support from considering weight to height ratio of athletes winning gold medals relative to the average in the general population.

\section{Conflicts of Interest}

The authors declare no conflicts of interest regarding the publication of this paper.

\section{References}

Beall, C. M. (2001). Adaptations to Altitude: A Current Assessment. Annual Review of Anthropology, 30, 423-456. https://doi.org/10.1146/annurev.anthro.30.1.423

Beall, C. M. (2006). Andean, Tibetan, and Ethiopian Patterns of Adaptation to High-Altitude Hypoxia. Integrative and Comparative Biology, 46, 18-24. https://doi.org/10.1093/icb/icj004

Disabled World Web Site (2017). https://www.disabled-world.com/calculators-charts/height-weight.php

Garhammer, J. (1993). A Review of Power Output Studies of Olympic and Power-Lifting: Methodology, Performance Prediction, and Evaluation Tests. Journal of Strength and Conditioning Research, 7, 76-89. https://doi.org/10.1519/00124278-199305000-00002

International-Weightlifting-Federation (2018). Technical and Competition Rules \& Regulations.

https://www.iwf.net/wp-content/uploads/downloads/2019/02/IWF_TCRR_01012019_v 2.pdf

Krane, V., Choi, P. Y. L., Baird, S. M. et al. (2004). Living the Paradox: Female Athletes Negotiate Femininity and Muscularity. Sex Roles, 50, 315-329. 
https://doi.org/10.1023/B:SERS.0000018888.48437.4f

Lev-Yadun, S. (2015). The Historic Role of Crocodiles and Other African Aquatic Pests in Current Sport Championships. Advances in Anthropology, 5, 122-125. https://doi.org/10.4236/aa.2015.52010

Popovic, S. (2017). Local Geographical Differences in Adult Body Height in Montenegro. Montenegrin Journal of Sports Science and Medicine, 6, 81-87.

Scott, R. A., Moran, C., Wilson, R. H., Goodwin, W. H., \& Pitsiladis, Y. P. (2004). Genetic Influence on East African Running Success. Equine and Comparative Exercise Physiology, 1, 273-280. https://doi.org/10.1079/ECP200434

Sherouse, P. (2016). Skill and Masculinity in Olympic Weightlifting: Training Cues and Cultivated Craziness in Georgia. American Ethnologist, 43, 103-115.

https://doi.org/10.1111/amet.12266

Sports-Reference (2016). Sports Reference Olympic Sports. https://www.sports-reference.com/olympics

Storey, A., \& Smith, H. K. (2012). Unique Aspects of Competitive Weightlifting. Sports Medicine, 42, 769-790. https://doi.org/10.1007/BF03262294

Trading Economics (2018). Taiwan Population 1974-2018. https://tradingeconomics.com/taiwan/population

Tucker, R., Santos-Concejero, J., \& Collins, M. (2013). The Genetic Basis for Elite Running Performance. British Journal of Sports Medicine, 47, 545-549. https://doi.org/10.1136/bjsports-2013-092408

U.S. Bureau of Labor Statistics, Division of Occupational Employment Statistics (n.d.). https://www.bls.gov/spotlight/2017/sports-and-exercise/home.htm

Wilber, R. L., \& Pitsiladis, Y. P. (2012). Kenyan and Ethiopian Distance Runners: What Makes Them So Good? International Journal of Sports Physiology and Performance, 7 , 92-102. https://doi.org/10.1123/ijspp.7.2.92

World Bank (2017). Countries and Economics. https://data.worldbank.org/country

Worldmeters (2018). Cook Island Population.

http://www.worldometers.info/world-population/cook-islands-population 